\title{
One Generic Mental Illness: A Principle-Based Psycho-Spiritual Explanation of General Factor $p$ and Its Application to Spiritually Informed Clinical Practice
}

\author{
Thomas M. Kelley $^{1(1)}$ \\ Wayne State University
}

\author{
William F. Pettit Jr. ${ }^{2 \mathbb{D}}$ \\ Creighton University
}

\author{
Judith Sedgeman $^{3}$ (D) \\ Sedgeman Consulting LLC
}

\author{
Jack Pransky $^{4}$ \\ Center for Inside-Out \\ Understanding
}

\begin{abstract}
${ }^{1}$ Professor Emeritus, Department of Criminology \& Criminal Justice, 3255 Faculty Administration Building, Wayne State University, Detroit, MI, USA. E-mail: aa5216@wayne.edu

${ }^{2}$ M.D., Adjunct Clinical Professor, Creighton University School of Medicine Department of Psychiatry, Phoenix AZ, USA.E-mail: bill@thedrspettit.com

${ }^{3}$ Ed.D., Mental Health Educator, Sedgeman Consulting LLC, 5616 Garden Lakes Drive, Bradenton, FL, USA, E-mail: sedgeconsult@gmail.com

${ }^{4}$ Ph.D., Director, Center for Inside-Out Understanding, 228 Wine St., Charlottesville, VT, USA. E-mail: jack@healthrealize.com
\end{abstract}

Corresponding author:

Thomas M. Kelley, Ph.D.

E-mail:

aa5216@wayne.edu

eISSN: 2458-9675

Received: 27.01.2021

Revision: 25.05.2021

Accepted: 03.06.2021

(C)Copyright 2021

by Author(s)

\begin{abstract}
Multiple forms of psychopathology appear to have one common liability typically referred to as general factor $\mathrm{p}$ (or p). The possibility of a general factor of psychopathology begs several questions. If something substantive exists that accounts for patterns of comorbidity across myriad forms of psychopathology, what exactly is it? If higher levels of this factor account for more severe and sustained psychological ill-heath, what explains it and its developmental progression? If this factor exists, does it account for varying levels of mental health and the apparent decline in mental health from childhood to mid-life? Does this factor have a common prevention and remediation? The authors offer a possible answer, a new psycho-spiritual explanation of general factor $\mathrm{p}$ grounded in understanding the way people's psychological life experiences are created via three universal Principles-Mind, Consciousness and Thought. Given this understanding of $\mathrm{p}$, we propose a process from $\mathrm{p}$ to psychopathology. Then we offer a prevention and remediation for the ill-effects of our view of $\mathrm{p}$ which we call factor $U$. Factor $U$ describes people's awareness and sufficient insight-based understanding of the way these three Principles manifest within everyone. Finally, we apply our view of $\mathrm{p}$ to clinical practice emphasizing empirically supported mental health education grounded in factor $U$ for preventing and remediating the ill-effects of $\mathrm{p}$, thus reducing psychopathology and its symptoms, and naturally restoring a state of innate mental well-being. Keywords:

General Factor $\mathrm{p} \bullet$ Universal Mind $\bullet$ Consciousness and Thought $\bullet$ Innate mental well-being • Mental health education
\end{abstract}




\section{One Generic Mental Illness: A Principle-Based Psycho-Spiritual Explanation of General Factor $p$ and Its Application to Spiritually Informed Clinical Practice}

A potential breakthrough may be imminent in the arenas of psychopathology and mental health. As Caspi and Moffit (2018) stated, “...empirical evidence has accrued to suggest that a single dimension is able to measure a person's liability to mental disorder, comorbidity among disorders, persistence of disorders over time and severity of symptoms" (p. 831). Research regarding internalizing, externalizing and psychotic symptoms across the life span appears to point to a general factor of psychopathology commonly referred to as general factor p (Caspi et al., 2014). New evidence from genetic, neuroscience and risk-factor research also points to a shared cause underlying an array of mental disorders (e.g., Hyman, 2019). The $\mathrm{p}$ factor appears to capture the shared variance across psychiatric symptoms, predict a multitude of poor outcomes and general life impairment (Selzam et al., 2018), and account for the co-occurrence of internalizing and externalizing disorders (Gluscgkoff, Jokela, \& Rosenstrom, 2019). This unidimensional factor reflects a model of psychopathology in which symptoms wax and wane, and individuals cycle through different psychiatric diagnoses over time because they have a general vulnerability to psychopathology rather than any specific disorder (Ronald, 2019).

In sum, the $\mathrm{p}$ factor is analogous to the general factor of intelligence (i.e., the "g" factor) that points to positive associations among several cognitive capacities (Deary, 2001; Jensen, 2001). In other words, as g reflects low to high cognitive functioning, $p$ reflects low to high severity of psychopathology. Lahey and associates (2012) stated, "If substantiated, this hypothesized "general" factor would have important implications for how the nature and etiology of mental disorders is conceptualized and studied" ( $p$. 971). To date, however, no one has determined exactly what this $\mathrm{p}$ factor is.

\section{Hypotheses Regarding $p$}

Several hypotheses have been offered regarding the identity of p. For example, Lahey, Applegate and associates (2012) noted that patterns of comorbidity among prevalent mental disorders load on negative affective states (e.g., externalizing, distress, fear) and proposed that $\mathrm{p}$ may represent negative emotionality. Carver, Johnson and Timpano (2017) speculated that the core fundamental mechanism of $\mathrm{p}$ may be poor emotional control including impulsive behavior and cognitive impulsivity (e.g., rumination). Lahey, Zald and associates (2014) posited that p may reflect a deficiency in intellectual functioning that increases one's vulnerability to mental ill-health. Caspi and Moffit (2018) proposed that " ... the symptoms of disordered thought processes will prove to be the most diagnostic elements of p" (p. 836).

The authors posit that rather than clarifying the nature of $p$, these kinds of speculations shine light on the unhealthy manifestations of our view of $p$. We further 
posit that to understand what $\mathrm{p}$ is would require a shift in focus away from the negative effects of $p$ to the very source of these ill-effects. In our view, what has been missing in the literature is an exploration of the nature of universal Principles ${ }^{1}$ at the source of or behind people's psychological life experiences. In other words, the answer to what $\mathrm{p}$ is would focus on people's awareness and insight-based understanding of the nature of three psycho-spiritual Principles that we posit reveal how people's psychological lives are created (Kelley, Pettit, Pransky, \& Sedgeman 2019; Kelley, Pettit, Sedgeman, \& Pransky, 2020).

We further posit that if people are oblivious of these Principles or have insufficient insight regarding the way these Principles manifest within everyone, they are prone to unintentionally misuse the Principles and thereby generate chronic mental stress in response to life's perceived challenges. In turn, this habitual mental stress typically produces psychological and somatic dysregulations that manifest as a host of internal symptoms and often a wide range of unhealthy behaviors. When a sufficient aggregation of these symptoms and behaviors has accrued, and treatment is sought, they are then recorded, using the DSM-5 and ICD-11, as one of myriad psychiatric diagnoses. This paper is an attempt to point in this contrasting direction; we posit that three universal Principles-Mind, Consciousness, and Thought ${ }^{2}$ - are at the source of all psychological experiences (e.g., feelings, perceptions, moods, and symptoms). We further posit that unawareness or insufficient insight regarding the way these Principles manifest within everyone is the primary liability underlying the etiology and persistence of myriad forms of psychopathology. In turn, we posit that sufficient insight-based understanding of these principles, which we refer to as "factor U", serves as a prevention and remediation for the ill-effects of our view of $\mathrm{p}$.

We realize that this shift in focus treads into realms where traditional psychology has not often explored; into the psycho-spiritual nature of reality. This area of inquiry, however, has been explored throughout history to the present day (e.g., Goddard, 2003; Hart, 1987; Mustananda, 1992; Rank, Rictor, \& Lieberman, 2015). Though unable to be examined by the human eye or later by the microscope, PET or MRI, the belief that people are composed of both spirit (psyche) and matter (soma) has been broadly accepted for centuries (for a review see Kelley, Pransky \& Lambert, 2015; Pransky \& Kelley 2014). Psyche is the Greek word representing the spiritual (i.e., formless) aspect of humanity often designated as mind, soul or the "breath of life". Psychology originally was the science or study of the soul or mind. However, unable to measure it within the scientific method, psychology abandoned the exploration of the psyche and focused primarily on biology and behavior. Behavior and biology have lent themselves far more easily to observation, measurement and research than do life, mind and soul. However, what if looking in the direction of the psyche holds answers that have heretofore been elusive, even if initially it does not appear easy to measure, research or even grasp? Sedgeman (1998) stated: 
... to grasp the difference between seeing Principles and learning theoretical knowledge ... requires science to examine something "new" in the context of insight and discovery-based learning... reflection as opposed to analysis... The study of the Three Principles ... is about what happens before there is any content - that is, before the formation of thought. (pp. 1-2)

Here, we first describe our Principle-based understanding of general factor $\mathrm{p}$ and propose the relationship of this view of $p$ to psychopathology and mental health. Then we attempt to explain how a factor, which we call factor $U$, provides a prevention and remediation for the detrimental effects of our view of p. Finally, we discuss the application of our view of $p$ to clinical practice emphasizing empirically supported mental health education grounded in factor $U$ for preventing and remediating the ill-effects of $p$, reducing psychopathology and its symptoms, and naturally restoring a state of innate mental wellbeing. When reflecting on our view of $p$, we respectfully request that readers step back from the logical positivist perspective which may have them view this understanding as difficult to measure or prove and, instead, consider its value in terms of a possible deeper, convergent, explanatory power (Mustakova-Possardt, 2002).

\section{A Principle-Based Understanding of $\mathbf{p}$}

Our understanding of general factor $p$ is grounded in the insights and work of Sydney Banks (1998, 2001, 2005). Banks's experience was first brought to the attention of psychology by primary prevention pioneer, Donald Klein (1998), who described Banks as follows:

... this man, without any attempt on his part to do so, had suddenly entered into a vastly different level of awareness, a form of spontaneous spiritual transformation about which William James had written in the early $1900 \mathrm{~s} . .$. his discoveries... were obviously worth exploring from the standpoint of preventive mental health... something very important was taking place... our most basic assumptions about human behavior were being challenged. (pp. 311-312)

Banks asserted that three Principles, which he referred to as Mind, Consciousness and Thought, are comprehensive, fundamental, universal truths that point to the formless source of everything that exists in form and are at the source of everyone's psychological experiences. Banks (1998) stated:

... You have to have the power of Mind and you have to be Conscious and you have to have Thought to relate to life. Anything else is a product of their usage. Therefore, it is virtually impossible to think of any mental activity that isn't a product of the Principles (p.41).

The search for universal Principles, or fundamental, primary, or general laws or truths from which all others are derived, has been present from the beginnings of all sciences. Regarding psychology, in 1890, William James (1981) asserted that the field could not be considered a science until and unless Principles were discovered. James pointed in the direction of Thought and Consciousness and saw a "spiritual 
self" connected to what he called "Absolute Mind, the essence of which we know nothing" (p. 329) (for a review see Pransky \& Kelley, 2014). While psychology did not appear to follow James's lead, Banks (2005) stood firm that he had uncovered the hoped-for Principles and stated “... Universal Mind, Universal Consciousness and Universal Thought are most definitely the Principles that turn psychology from a guesswork philosophy into a working science" (p. 37).

Banks encouraged and supported efforts of mental health professionals in moving in this direction. He insisted, however, they look beyond an intellectual understanding of the Principles to the fundamental truths representing an original source before form. A psycho-spiritual understanding grounded in Banks's insights has evolved worldwide and is now commonly referred to in the literature as The Three Principles or Three Principles/Innate Health (Kelley, Pranksy, \& Lambert, 2016a, 2016b; Pransky \& Kelley, 2017). In sum, Banks asserted that Mind, Consciousness and Thought represent the unifying, undergirding Principles that William James originally envisioned but had never fully realized. We offer this information because we posit this new perspective brings clarification to the prevailing speculations regarding general factor $\mathrm{p}$ and elucidates a prevention and remediation of its significant detrimental effects.

\section{The Three Principles}

Banks (1998) asserted that Mind, Consciousness and Thought are metaphors that point to fundamental, primary, universal truths or Principles. He further asserted that all human beings continually utilize these three Principles to create their unique life experiences. What follows is a brief review of the three Principles and how we posit they manifest within everyone (for an in-depth review see Banks, 1998; Pransky \& Kelley, 2014).

\section{Universal Mind}

What is the fundamental truth of Universal Mind? Universal Mind points to the fact that the universe is intelligent; that there would be no creative forces in the universe, nothing living, if not for an intelligent life force energy. Banks (2005) asserted "Universal Mind is the intelligence of all things, whether in form or formless. Universal Mind holds the secret to all psychological functioning" (p. 59). Banks (2005) continued:

... There is only one Universal Mind common to all, and wherever you are it is with you always... constant and unchangeable... The personal mind is in a perpetual state of change. Universal Mind and personal mind are not two minds thinking differently, but two ways of using the same mind... All humans have the ability to synchronize their personal mind with their impersonal mind to bring harmony into their lives." (p. 32-35) 


\section{Universal Consciousness}

What is the fundamental truth of Universal Consciousness? Universal Consciousness points to the fact that people must somehow be conscious of life or they would have no experience of it; that without Consciousness, human beings would be unaware of their own existence or anything that happens within it or to it. Banks (2001) stated, "Universal Consciousness... enables us to observe and experience the existence and workings of the world we live in" (p. 97). On a personal level, Consciousness animates people's thoughts via their physical senses and forms their moment-to-moment psychological experiences. Banks (2005) referred to personal consciousness as " ... the gift of awareness ... [which] allows for the recognition of form, form being the expression of Thought". Banks (2005) also distinguished levels of consciousness and stated:

... as our consciousness descends, we lose our feelings of love and understanding and experience a world of emptiness, bewilderment, and despair. As our consciousness ascends, we regain purity of Thought and, in turn, regain our feelings of love and understanding. (p. 40)

Banks (1998) further asserted, counter to the prevailing paradigm, that "Mental health lies within the consciousness of all human beings, but it is shrouded and held prisoner by our own erroneous thoughts" (p. 41). In this regard, the authors posit that the problems for which people seek psychotherapy are the result of people experiencing and/or behaving in response to the "reality" they see at lower levels of consciousness. Each level looks and feels very real at the time, but it is only "real" when seen from that level of consciousness, and the level through which people see the world can change at any moment with their next thought. Banks indicated that with incremental insights a person's level of consciousness/awareness/understanding increases, and one's experience of the world changes.

\section{Universal Thought}

What is the fundamental truth of Universal Thought? Universal Thought points to the fact that every person has the power to create thoughts. Banks (1998) stated "Thought is the creative agent we use to direct us through life" (p.47). People can use the power of Thought in an infinite number of ways; to create happiness or sadness, forgiveness or anger, exhilaration or depression and everything in between. Banks (1998) stated "Thought is the master key that opens the world of reality to all living creatures. ... Thought is not reality, but it is through thought that our realities are created" (p. 49). Thought, as a Principle, does not refer to people's already-formed thoughts or thought products (e.g., feelings, perceptions, beliefs). Rather, the Principle of Thought refers to the fact that all people continually use the power of Thought to create thoughts that enlivened via consciousness become their psychological experiences. 
In sum, what Banks realized is how everyone creates "reality" the same way via their use of these three universal Principles and, therefore, how everyone creates a different "reality" moment-to-moment. When we say "use" of the three Principles, we are not suggesting that people "do something"-that tools, techniques or strategies are necessary. Rather, we mean everyone uses the three Principles to have psychological experience in the same way everyone uses gravity to stay anchored to Earth. Although some would dispute Banks's notion of the way these Principles create people's psychological lives, we posit they would have to be using these very Principles to do so.

\section{A Process from Our View of $p$ to Psychopathology}

\section{Our View of General Factor $p$}

The authors posit that the Principles of Mind, Consciousness and Thought describe the source of everyone's psychological experiences and the power to navigate through life. Whether one realizes it or not, these three Principles are always operating within everyone giving them their unique experience of life. Like any system, ${ }^{3}$ with sufficient understanding, people can use a system's undergirding Principles wisely or, if unrecognized or insufficiently understood, people can misuse them. We posit that whether people allow these Principles to operate in their best interest or to the detriment of their mental well-being stems from their awareness of the Principles and sufficient insight regarding their nature. Thus, we posit that general factor $\mathrm{p}$ describes people's unawareness or insufficient insight-based understanding of the way the Universal Principles of Mind, Consciousness and Thought manifest within everyone.

\section{Innocent Misuse of the Principle of Thought}

Absent awareness or sufficient understanding of the three Principles, people are prone to misuse the Principle or power of Thought. In other words, people are susceptible to taking on disordered habits of thinking and, in turn, to believe and often act on the ideas, impulses and feelings this disordered personal thinking creates (Kelley, Pettit, Sedgeman \& Pransky, 2019). In this regard, the consensus of psychopathology research is chronic disordered thinking is a common factor in most forms of psychopathology. For example, Verkuil and associates (2012) stated:

... in psychopathology research, perseverative cognitive processes (i.e., stress-producing cognitions that are repeatedly activated) like worry and rumination have received increasing attention... and have been recognized as core etiological factors in the onset and maintenance of several psychological disorders. (p.88)

Perseverative cognitive processes and other forms of maladaptive repetitive thought (e.g., Watkins, 2008) have been found to relate with depressed mood and 
pessimism, clinical depression, heightened anger, PTSD symptomology, increased anxiety, difficulty concentrating, poor problem solving, poor sleep quality, reduced quality of life, worse self-reported physical health, worse cardiovascular function and weakened immune system function (Brosschot, Gerin, \& Thayer, 2006; Ehring, Frank, \& Ehlers, 2008; Jamshaid, Malik, Haider, \& Jamshad, 2020; S. Hong, 2007; Lyubomirsky, \& Nolen-Hoeksema, 1995; McLaughlin, Borkovec, \& Sibrava, 2007; Rusting \& Nolen-Hoeksema, 1998; Zawadzki, Graham, \& Gerin, 2013; Ottaviani et al., 2016). The findings of these individual studies are consistent with several metaanalyses demonstrating the negative effects of chronic unrecognized misuse of the Principle of Thought across a wide range of psychological and somatic health (e.g., Zawadzki, Graham, \& Gerin, 2013).

Furthermore, chronic misuse of the power of Thought to control one's disordered thoughts after they are created (e.g., suppression, cognitive self-consciousness, self-beratement, thought reconditioning) has also been identified as an important feature of numerous psychological disorders such as obsessive-compulsive disorder, posttraumatic stress disorder, hypochondriasis, social phobia, insomnia, and depression (e.g., Abramowitz, Whiteside, Kalsey, \& Tilin, 2003; Harvey, 2002). Finally, additional research suggests that the unconscious perseverative thoughts may play an even larger role in creating and sustaining psychological and somatic disorders (e.g., Brosschot, Verkuil, \& Thayer, 2010).

\section{Chronic Mental Stress}

Chronic misuse of the of Principle of Thought and the discomforting symptoms it spawns regarding the past (e.g., guilt, resentment, unresolved grief), the present (e.g. self-consciousness, ego, drivenness) and the future (e.g. apprehension, fear, terror) generally results in chronic mental stress. In this regard, another consensus of psychopathology research is multiple forms of mental ill-health, often with concomitant physiological consequences, are initiated and perpetuated by chronic activation of the stress response system. Chronic mental stress typically results in overproduction of cortisol, noradrenaline and other stress hormones, heightened inflammation, changes in the reactivity of the hypothalamic-pituitary-adrenal (HPA) axis and disturbances in homeostasis in the neuro-transmitters and receptors and the brain's neuro-circuitry (Dinan \& Cryan, 2012; Kahn \& Kahn, 2017; Kaufer et al., 1998). Overexposure to stress hormones can disrupt the immune system and the microbiota, the digestive system, the reproductive system and the growth processes (Kahan \& Kahan, 2017; Papadopoulos \& Cleare, 2012). This complex natural alarm system also communicates with regions of the brain that control mood, motivation and fear, potentially creating a variety of negative and often debilitating psychological symptoms (Kent \& Rosanoff, 2007). These dysregulations can produce multiple 
somatic changes, including lowered pain tolerance, sleep disturbance, muscle tension, and autoimmune dysregulation that add to the psychological burden (i.e., allostatic load) (Luyten et al., 2008). If these symptoms progress with sufficient severity and persistence, and treatment is sought, they are then categorized as common psychiatric disorders such as major depression, generalized anxiety and social phobia. At severe levels, they are classified as psychotic experiences and diagnoses.

\section{Psychopathology: Chronic Concealment of Innate Mental Well-Being}

Mental health research points to an often-gradual decline in people's mental health from childhood to adulthood. Kent and Rosanoff (2007) stated "No sharp distinction can be drawn between mental health and mental disease; a large collection of material shows a gradual and not an abrupt transition from the normal state to pathological states" (p. 317). For example, in the second wave of the Child Development Supplement (CDS-II) of the Panel Study of Income Dynamics (PSID), a comprehensive set of subjective well-being items was administered to 1,234 youth ages $12-18$. Based on their responses, Keyes (2006) classified these youth as flourishing (38\%), moderately mentally healthy $(56 \%)$ or languishing $(6 \%)$. Flourishing was the most prevalent category among youth ages 12-14 (48.8\%); however, moderate mental health was the most prevalent category among youth ages $15-18$ (51.5\% moderate; $39.9 \%$ flourishing). These findings and those of other national and international studies (Guo, Tomson, Keller, \& Sodweqvist, 2018; Keyes, 2007; Keyes et al., 2008; Lim, 2014; Proctor, et al., 2009; Salama-Younes, 2012; Singh, Bassi, Junnakar, \& BNegri, 2015; Suldo \& Shaffgwe, 2008) suggest that by late adolescence the mental health of most people is far less than flourishing. Even more concerning, as adolescents age into adulthood, the percentage classified as flourishing appears to decline even more. Keyes (2007) stated:

Very few adults... could be classified as genuinely mentally healthy. Less than 2 in 10 adults were completely mentally healthy... anything less than flourishing is associated with increased impairment, disability and burden to self and society ... Flourishing-reported ... the healthiest psychosocial functioning (i.e., low helplessness, clear goals in life, high resilience, and high intimacy), the lowest risk of cardiovascular disease, the lowest number of chronic physical diseases, the fewest health limitations of activities of daily living, and lower health care utilization. (pp. 95, 103).

Furthermore, Caspi and associates (2020), using data from the Dunedin Birth Cohort Study, followed a group of 1037 participants from age 3 to age 45. During this 42-year interval, psychiatric disorders were assessed 9 times, starting at age 11 . The researchers reported that by midlife, $86 \%$ of the cohort met the criteria for a mental health disorder at some point in their life. The onset of disorder occurred by adolescence for $59 \%$ of participants. The diagnostic category (e.g., internalizing, or externalizing disorder) often changed over time. According to the researchers “... people who sustain enduring mental health are rare exceptions $(14 \%$ in our 
cohort)" p. 14. They concluded there needs to be more of a transdiagnostic and lifecourse perspective of mental disorders that incorporates a more general concept of psychopathology which expresses itself in different ways over time (i.e., factor p).

We posit that the primary source of the apparent gradual decline in people's mental health from adolescence to mid-life, and the diversity in disorders experienced by many over time, is unawareness or insufficient understanding of the three Principles. Banks (2001) stated, "Mental health lies within the consciousness of all human beings, but it is shrouded and held prisoner by our own erroneous thoughts" (p. 41). The nature of this innate mental health is the pure spiritual power of Universal Mind. This power manifests within each human being, from birth, as a natural state of mental well-being. This is recognized as an internal state of contentment, or ease. The only disruption of this natural state of well-being arises from the innocent misuse of the Principle of Thought. Banks described the power of Thought as the missing link between mental sickness and mental health.

Unfortunately, most people are unaware or have insufficient insight regarding the way the principles of Mind, Consciousness and Thought create their own and everyone else's psychological experiences. Absent sufficient understanding of these Principles, people are prone to innocently misuse the Principles and thereby obscure or cover over their natural state of mental well-being. We propose, however, that people can be assisted to realize and recognize, in the moment, that what they actually "see" is a temporary manifestation created by the three Principles. If people do not realize this fact, they will tend to take their disordered thoughts to heart and often act on whatever "reality" these thoughts create. However, if people recognize this fact, they will be less likely to view their momentary thoughts as "the truth" or the way things really are and thus, will be less likely to believe and act on these thoughts.

We further posit that people can be helped to see what they experience when the personal mind quiets down, and what they feel like at those times. They can be assisted to see that only their personal thinking can get in the way of this naturally healthy state. When people gain an insight-based understanding the three Principles, recognize the inextricable connection between their thoughts and their psychological experiences, realize the availability of innate well-being via a quiet mind, and can access this understanding in the moment, we posit that the common precursor to psychopathology will decrease.

In this regard, we reiterate that viewed through the lens of our Principle-based understanding of $p$, the prevailing kinds of hypotheses regarding the identity of $p$ (e.g., negative emotionality, poor emotional control, impulsive behavior, vulnerability to psychopathology, symptoms of disordered thought processes) do not illuminate $\mathrm{p}$. Rather, these speculations shine light on the unhealthy manifestations of our view 
of $\mathrm{p}$. More importantly, we posit that these ill-effects are also natural products of the three Principles in action. In other words, emotional instability, impulsivity, symptoms of disordered thought processes, etc., (i.e., allostatic load) serve as internal alarms meant to alert people that they are misusing the three Principle and obscuring their innate mental health.

\section{Factor U: The Prevention and Remediation of the Ill-Effects of $p$}

The authors have posited that general factor $\mathrm{p}$ describes people's unawareness or insufficient insight-based understanding of the Universal Principles of Mind, Consciousness and Thought. Thus, we further posit that awareness and sufficient insight regarding the nature of these Principles serves as both a prevention and remediation to the unhealthy manifestations of $\mathrm{p}$. Therefore, what we define as factor $\mathrm{U}$ (or $\mathrm{U}$ ) describes people's awareness and sufficient understanding, via insight, of the way the universal Principles of Mind, Consciousness and Thought manifest within everyone. Another way of seeing this is that people come into the world in a pure state of consciousness in which they naturally experience mental well-being. However, absent sufficient understanding of the three Principles, people are prone to innocently misuse the Principles and cover over or obscure this innate health. Banks (1998) stated:

[Everyone] is subject to what I would call psychological viruses ... such as greed, hate, jealousy, desire and envy just to name a few ... such viruses are as natural as breathing and nobody journeys through this life completely immune from them. When you are suffering from such a virus, you are not sick per se ... you are temporarily and innocently not thinking straight. (pp. 87-88)

\section{Application to Clinical Practice}

The application of this Principle-based understanding of $p$ to clinical practice has been described in detail elsewhere (for a review see Kelley \& Pransky, 2013 and Kelley, Pransky, \& Sedgeman, 2014). In brief, practitioners of this understanding typically view themselves as teachers or mental health educators. This education has as its goal awakening people's understanding of the "inside-out" creation of everyone's psychological experiences via the three Principles, and the availability of innate mental well-being via a quiet mind. This education assumes that each person has an innate understanding of the truths to which these Principles point, and that this awareness can be awakened. ${ }^{4}$ Thus, this is a process of recognition (i.e., knowing again) and realization; in contrast to feeding information to the personal intellect. Banks (2001) stated:

[The Three Principles describe] ... the missing link between our psychological nature and our spiritual nature... As we start to regain the true relationship between our personal intelligence and the spiritual wisdom that lies within, we develop a higher degree of intelligence and common sense. This, in turn, clears up our misguided lives. (p. $74 \& 76$ ) 
Practitioners of this understanding are assumed to have a sufficient level of insight regarding the three Principles, have applied this insight to their own lives with improved results, and generally live in a state of health and well-being themselves. Practitioners focus on the innate health in their clients, as opposed to focusing on the external, illness, diagnosis or problematic behavior. They do not view even the most troubled people as damaged or in need of fixing. Instead, they see them as whole and complete. While this practice is free-form, in that there are no specific techniques, it is founded on the "health of the helper", the unconditional faith of practitioners in the health of their clients, and practitioners ability to listen deeply and trust their own insights to guide them (Kelley \& Pransky, 2013).

Practitioners attempt to draw out the innate well-being of their clients, in the moment, from their own intuition and wisdom as they work with them. As they listen and respond, clients have their own insights and their innate health surfaces as they see, for themselves, they are not damaged, they can access well-being and wisdom, and they are not the prisoner of their own worse thoughts. Pransky and Kelley (2014) stated:

The primary difference between traditional forms of psychotherapy and three-Principles psychotherapy is that with traditional therapies, the feelings and problems people experience are considered real things that one can be helped to deal with constructively in many varying ways, depending on the therapy. In three Principles therapy, the feelings and problems are considered to be essentially illusions or mirages created by one's power of Thought. The solution is to see these feelings and problems for the self-creations they truly are via new insight arising from wisdom, thereby raising their level of consciousness. These new ways of thinking can only be realized through new insight (as opposed to cognitive restructuring). (p. 61)

As people's insight regarding the three Principles deepens, they realize that their psychological experiences are created via the power of Thought and are transient as their thoughts change. They recognize that every so-called reality is a fleeting, ephemeral product of their own minds at work. When people grasp the inextricable connection between their thoughts and their feelings, perceptions, states of mind and behavior, they gain perspective on life. Shifts in their experience show up as "thought events" rather than effects of past or present circumstances or how other people treat them. In turn, they are less likely to view their momentary thinking and its manifestations as "the truth" or the way things really are and to act indiscriminately on the "realities" this thinking creates. More importantly, they realize that beneath their thinking at their spiritual essence they are perfectly healthy, whole and complete.

Everyone experiences disordered thinking and its symptoms (e.g., lowered mood, increased anxiety, mental confusion). However, when people relate to these symptoms as helpful information about the quality of their thinking, they are less likely to believe in the "reality" of this thinking and more likely to regain and sustain psychological well-being. In this regard, Teasdale and associates (2001) reported that 
assisting people to change how they relate to their negative thoughts and insecure feelings may be more useful than teaching techniques to modify or recondition their thoughts and beliefs. In other words, rather than viewing their thoughts as "true" or "real" people are helped to relate to them as merely "events in the mind". The researchers concluded:

This perspective ... represented a shift in our fundamental understanding. Previously, we, and others, had seen de-centering as one of a number of things going on in cognitive therapy. Our analysis suggested that it was central... If such de-centering did not take place, patients would be left arguing with themselves about whether their thoughts were true or not, marshalling evidence for or against a negative thought and at risk of simply getting caught up in the thought pattern. (p. 24)

Through mental health education grounded in factor $\mathrm{U}$, we posit that people can be assisted to see that their "psychological viruses" disappear when the personal mind quiets down. They can recognize that as they pay less attention to their disordered personal thoughts, their mind quiets naturally and they become more present. As people live more "in the now" they access innate well-being. Banks (1998) stated:

When... people refer to the now, they mean the personal mind is free from the contaminants of yesterday's memories and fears. This in turn frees the mind to see with clarity things as they are, not through distorted memories and apprehensions. Living in the now requires a clear mind. (p. 100)

\section{Testing Our View of Factors p and U}

Considerable preliminary empirical evidence exists in support the efficacy of mental health education grounded in factor $U$ for reducing psychopathology and its symptoms and improving and sustaining mental well-being. For example, Sedgeman and Sarwari (2006) reported that HIV-positive patients receiving this education showed a significant reduction in stress and anxiety which was sustained at 8-week follow-up. Banerjee, Howard and Mansheim (2007) reported that females in residential substance abuse treatment receiving this education showed significant positive outcomes regarding substance use, criminal justice involvement, employment, housing, adverse effects of substance use and mental wellbeing. Halcon, Robertson and Monsen (2010) reported that Somali and Ethiopian women refugees receiving this education showed a significant decrease in posttraumatic stress. Kelley (2011) reported that adults on probation receiving this education showed a significant improvement in mental wellbeing and mindfulness. Kelley, Pransky and Lambert (2015a) reported that adults receiving this education showed a significant improvement in nonattachment and regulating negative emotions, and a significant reduction in rumination, depression and anxiety. Kelley, Pransky, and Lambert (2015b) reported that adults receiving this education reported less dependence on 
techniques (e.g., meditation) to experience mindfulness and heightened wellbeing during negative states of mind.

Furthermore, El-Mokadem, DiMarko, Kelley, \& Duffield (2020) reported that compared with a waitlist control group, participants diagnosed with chronic fatigue syndrome receiving this education reported a significant improvement in mental and physical wellbeing and a significant reduction in depression, anxiety, fatigue and pain interference symptoms. Kelley, Alexander, and Pransky (2017) reported that compared to a waitlist control group, children and adolescents receiving this education showed a significant improvement in resilience and that "high-risk" youth showed a significant decrease in risky behavior. Kelley, Hollows, Pransky and associates (2021) reported that compared with a control group, participants in prison for sexual violence receiving this education showed a significant improvement in mental wellbeing, and a significant reduction in low self-control, depression, anxiety and anger. Kelley Hollows, Savard and associates (2017) reported that compared to a waitlist control group, male residents in a U.K. prison receiving this education showed a significant improvement in wellbeing and purpose in life, and a significant decrease in depression, anxiety, and anger which were maintained at follow-up. Kelley, Pransky and Lambert (2016) reported that adults receiving this education showed a significant increase in hedonic wellbeing, eudiamonic well-being, social wellbeing, flourishing mental health, mindful attention, mindful acceptance, flow and mental wellbeing. Reece-Evans and Pevalin (2017) reported that students and staff at a U.K. secondary school receiving this education showed a significant increase in mental wellbeing that was maintained at follow up.

Additional research is needed to test our understanding of general factor $\mathrm{p}$ and the efficacy of factor $U$ for preventing and remediating its ill-effects. In this regard, the authors are preparing to study adults exposed to adverse childhood experiences (ACEs). We chose these participants to study because the consensus of ACEs research is childhood trauma is a common factor in the history of people with a variety of mental illnesses including mood disorders, anxiety disorders, behavioral disorders, substance use disorders, schizophrenia and psychosis (Felitti et al., 1998). The cumulative ACEs score for participants followed over time shows a strong, graded relationship with numerous somatic, social and behavioral problems throughout life (Merrick, Ford, Ports, \& Guinn, 2018). Caspi and Moffit (2018) stated:

...it is difficult to identify a disorder in which childhood maltreatment is not linked than to identify a disorder to which it $i$ linked with specificity... Childhood maltreatment also predicts disorder that is comorbid, persistent, and even treatment resistant... [however] although maltreatment is a potent risk factor for developing psychiatric disorders, it is apparent that there are marked individual differences in response to it, and many people who are victimized remain healthy (p. 839). 
We speculate that participants' psychological and somatic symptoms will relate directly with factor $p$ and inversely with factor $U$, and that participants' mental wellbeing will relate inversely with $p$ and directly with $U$.

\section{Conclusion}

The authors respectfully encourage mental health researchers in their search for general factor $p$ to consider shifting their primary focus away from the content or products of people's already-formed thoughts toward what we are calling factor U; awareness and sufficient insight-based understanding of the universal Principles of Mind, Consciousness and Thought; recognition of the role of the power of Thought in creating people's psychological experiences; and the realization that all people have innate mental well-being readily accessible whenever the personal mind quiets. We posit that these are understandings that can be gained (i.e., factor $\mathrm{U}$ ), and when they are, they serve as a prevention and remediation for the ravages of our view of general factor $\mathrm{p}$.

Carver, Johnson, and Timpano (2017) stated:

The idea of identifying core functional mechanisms that increase vulnerability to psychopathology in a very broad way is an exciting one. It would open the doors for rethinking both etiological mechanisms and commonalities in treatment approaches (p. 881).

The authors posit that our understanding of general factor $\mathrm{p}$ - unawareness and insufficient insight regarding how the Universal Principles of Mind, Consciousness and Thought manifest within everyone to create their psychological lives-represents the "core fundamental mechanism" that crosses myriad forms of psychopathology. Banks (1998) asserted, "There need only be one generic mental illness; an inability to see the role of [Universal Mind, Consciousness and] Thought" (p. 38).

\section{Endnotes}

1. We capitalize the word "Principle" to distinguish it from its more common usage such as tenets, guidelines, characteristics, or ethical standards.

2. When we capitalize Mind, Consciousness, and Thought they are meant to depict formless, universal powers, abilities, or faculties. When these terms are not capitalized, they are meant to refer to personal mind, personal consciousness, and personal thought or thoughts.

3. When we use the term "system" we mean an ordered and comprehensive assemblage of facts, principles, or doctrines in a particular field of knowledge or thought.

4. Banks (1998) defined insight as, “... a realization of knowledge from within the depths of our own consciousness" (p.15). 


\section{References}

Abramoweitz, J. S., Whiteside, S., Lynam, D., \& Kelsey, S. (2003). Is thought-action fusion specific to obsessive-compulsive disorder? A mediating role of negative affect. Behavior Research Therapy, 41(9), 1069-1079, DOI: 10.1037/1064-1297.11.3.210

Banerjee, K., Howard, M., Mansheim, K., \& Beattie M. (2007). Comparison of health realization and 12-step treatment in women's residential substance abuse treatment programs. The American Journal of Drug and Alcohol Abuse, 33, 207-215. DOI: 10.1080/00952990601174758

Banks, S. (1998). The missing link. Vancouver, BC: Lone Pine Publishing.

Banks, S. (2001). The enlightened gardener. Vancouver, BC: Lone Pine Publishing.

Banks, S. (2005). The enlightened gardener revisited. Vancouver, BC: Lone Pine Publishing.

Brosschot, J. F., Gerin, W., \& Thayer, J. F. (2006). The perseverative cognition hypothesis: A review of worry, prolonged stress-related physiological activation, and health. Journal of Psychosomatic Research, 60(2), 113-124. DOI: 10.1016/j.jpsychores.2005.06.074

Carver, C. S., Johnson, S. L., \& Timpano, K. R. (2017). Toward a functional view of the p factor in psychopathology. Clinical Psychological Science, 5(5), 880-889, DOI: 10.1177/2167702617710037

Caspi, A., Houts, R. M., \& Ambler, A. (2020). Longitudinal assessment of mental health disorders and comorbidities across 4 decades among participants in the Dunedin Birth Cohort Study. Jama Network Open, 3(4), DOI:10.1001/jamanetworkopen.2020.3221

Caspi, A., Houts, R. M., Belsky, D. W., Goldman-Mellor, S. J., Harrington, M., \& Moffit, T. E. (2014). The p-factor: One general psychopathology factor in the structure of psychiatric disorders? Clinical Psychological Science, 2014, 2, 119-137, DOI: 10.1177/2167702613497473

Caspi, A, \& Moffit, T. E. (2018). All for one and one for all: Mental disorders in one dimension. American Journal of Psychiatry, 175(9), 831-844, DOI: 10.1176/appi.ajp.2018.17121383

Deary, I. J. (2019). Intelligence, a very short introduction. Oxford, England: Oxford University.

Dinan, G. D., \& Cryan, J. F. (2012). Regulation of the stress response by the gut microbiota: Implications for psychoneuroendocrinology. Psychoneuroendocrinology, 37(9), 1368-1378. DOI: $10.1016 /$ j.psyneuen.2012.03.007

Ehring, T., Frank, S., \& Ehlers, A. (2008). The role of rumination and reduced concreteness in the maintenance of posttraumatic stress disorder and depression following trauma. Cognitive Therapy and Research, 32, 488-506, DOI: 10.1007/s10608-006-9089-7

El-Mokadem, J., DiMarko, K., Kelley, T. M., \& Duffield, L. (2020). Three Principles/Innate Health: The efficacy of a new psycho-spiritual mental health education intervention for people with chronic fatigue syndrome. Spirituality in Clinical Practice, DOI: 10.1037/scp0000232

Felitti, V. J., Anda, R. F., Nordenberg, D., Williamson, D. F., Spitz, A. M., et al., (1998). Relationship of childhood abuse and household dysfunction to many of the leading causes of death in adults: The Adverse Childhood Experiences (ACE) Study. American Journal of Preventive Medicine, 14(4), 245-258, DOI: 10.1016/s0749-3797(98)00017-8

Glusegkoff, K., Jokela, M., \& Rosenstrom, T. (2019). The general psychopathology factor: Structural stability and generalizability to within-individual changes. Frontiers in Psychiatry, DOI: $10.3389 /$ fpsyt.2019.00594

Goddard, N. (2005). The Neville reader. Camarillo, CA: DeVoss. 
Guo, G., Tomson, G., Keller, C., \& Soderqvist, F. (2018). Psychometric evaluation of the Mental Health Continuum-Short Form in Chinese adolescents - a methodological study. Health Quality Life Outcomes, 13, 198, DOI: 10.1186/s12955-015-0394-2

Halcon, L. L., Robertson, C. L., \& Monsen, K. A. (2010). Evaluating health realization for coping among refugee women. Journal of Loss and Trauma, 15, 408-425, DOI: $10.1080 / 15325024.2010 .507645$

Hart, W. (1987). Vipassana meditation as taught by S. N. Goenka: The art of living. SanFrancisco, CA: Harper.

Harvey, A.G. (2002). A cognitive model of insomnia. Behavior Research Therapy, 40(8), 869-893, DOI: 10.1016/s0005-7967(01)00061-4

Hofferth, S., Davis-Kean, P. E., Davis, J., \& Finkelstein, J. (1997). The child development supplement to the panel study of income dynamics. Ann Arbor, MI: Survey Research Center, Institute for Social Research, The University of Michigan.

Hong, R. Y. (2007). Worry and rumination: Differential associations with anxious and depressive symptoms and coping behavior. Behaviour Research and Therapy, 45, 277-290, DOI: 10.1016/j.brat.2006.03.006

Hyman, S. E. (2019). New evidence of shared risk architecture of mental disorders. JAMA Psychiatry, 76(3), 1127-1131, DOI:10.1001/JAMAPSYCHIATRY.2018.4269

James, W. (1981). The principles of psychology. Cambridge, MA: Harvard University Press.

Jamshaid, O. S., Malik, N. I., Haider, A. A., \& Jamshad, S. (2020). Overthinking hurts: Rumination, worry and mental health of international students in China during Covid-1 pandemic. Paper presented at the International Joint Conference on Arts and Humanities. Indonesia.

Jensen, A. R. (1998). Human evolution, behavior, and intelligence. The g factor: The science of mental ability. 1998; Westport, CT, US: Praeger Publishers/Greenwood Publishing Group.

Kahn, S., \& Khan, R. A. (2017). Chronic stress leads to anxiety and depression. Annals of Psychiatry and Mental Health, 5(1), 1091, DOI: 10.12691/ajssm-6-3-2

Kaufer, D., Friedman, A., Seidman, S., \& Sore, H. (1998). Corrigendum: Acute stress facilitates longlasting changes in cholinergic gene expression. Nature, 393(6683), 373-377, DOI: 10.1038/30741

Kelley, T. M. (2011). Thought recognition and psychological well-being: An empirical test of principle-based correctional counseling. Counseling and Psychotherapy Research, 11(2), 140147, DOI: $10.1080 / 14733145.2010 .485689$

Kelley, T. M., Alexander, J., \& Pransky, J. (2017). Drawing-out resilience in children and highrisk adolescents via exposing them to three psycho-spiritual principles. Journal of Child and Adolescent Behaviour. 5(2), DOI: 10.4172/2375-4494.1000343

Kelley, T. M., Hollows, J., Pransky, J., Kryvanos, A., \& Bowen, S. (2021). The efficacy of Three Principles Correctional Counseling for improving the mental health and self-control of people incarcerated for sexual violence. Violence Against Women. DOI: 10.1177/10778012211022783

Kelley, T. M., Hollows, J., Savard, D., Lambert, E. G., \& Pransky, J. (2017). Teaching health vs. treating illness: The efficacy of three principles correctional counseling with people in an English prison. Journal of Offender Therapy and Comparative Criminology, 62(9), 2831-2856, DOI: $10.1177 / 0306624 X 17735253$

Kelley, T. M., Pettit, W. F., Pransky, J., \& Sedgeman, J. (2019). A new “inside-out” view of general factor p. European Psychiatry, 2019, 61, 85-87, DOI: 10.1016/j.eurpsy.2019.06.009 
Kelley, T. M., Pettit, W. F., Sedgeman, J., \& Pransky, J. (2020). Psychiatry's pursuit of euthymia: Another wild goose chase or an opportunity for principle-based facilitation? International Journal of Psychiatry in Clinical Practice, DOI: 10.1080/13651501.2020.1837182

Kelley, T. M., \& Pransky, J. (2013). Principles for realizing resilience: A new view of trauma and human resilience. Journal of Traumatic Stress Disorders and Treatment, 2(1), DOI: 10.4172/2324-8947.1000102 2(1)

Kelley, T. M., Pransky, J., \& Lambert, E. (2015a). Realizing improved mental health through understanding three spiritual principles. Spirituality in Clinical Practice, 2(4), 267-281. DOI:1 $0.1080 / 19349637.2016 .1215855$

Kelley, T. M., Pransky, J., \& Lambert, E. A. (2015b). Inside-out or outside-in: Understanding spiritual principles versus depending on techniques to realize improved mindfulness/mental health. Journal of Spirituality in Mental Health 17(3), 1653-1662, DOI: 10.1080/19349637.2014.998752

Kelley, T. M., Pransky, J., \& Lambert, E. (2016a) Understanding spiritual principles or depending on techniques to realize and sustain optimal mental health. Spirituality in Mental Health, 18(3), 217-238, DOI: 10.1080/19349637.2015.1087361

Kelley, T. M., Pransky, J., \& Lambert, E. (2016b). Realizing improved mindfulness/flow/mental health through understanding three spiritual principles. Journal of Spirituality in Mental Health, 19(2), 133-150, DOI: 10.1080/19349637.2016.1215855

Kelley, T. M., Pransky, J., \& Sedgeman, J. (2014). Realizing resilience in trauma exposed juvenile offenders: A promising new intervention for juvenile justice professionals. Journal of Child and Adolescent Trauma, 7, 143-151, DOI: 10.1007/s40653-014-0018-8

Kent, A. H., \& Rosanoff, A. J. (2007). A study of association in insanity. Dodo Press.

Keyes, C. L. M. (2006). Mental health in adolescence: Is America's youth flourishing? American Journal of Orthopsychiatry, 76(3), 395-402, DOI: 10.1037/0002-9432.76.3.395

Keyes, C. L. M. (2007). Promoting and protecting mental health as flourishing: a complementary strategy for improving national mental health. American Psychologist, 62(2), 95-108, DOI: 10.1037/0003-066X.62.2.95

Keyes, C. L. M., Wissing, M., Potgieter, J. P., et al. (2008). Evaluation of the mental health continuum-short form (MHC-SF) in Setswana-speaking South Africans. Clinical Psychology \& Psychotherapy, 15(3), 181-192, DOI: 10.1037/0003-066X.62.2.95

Klein, D. C. (1988). The power of appreciation. American Journal of Community Psychology, 1988; 16, 305-324, DOI: 10.1007/BF00919373

Lahey, B. B., Applegate, B., Hakes, J. K., et al. (2012). Is there a general factor of prevalent in psychopathology during adulthood? Journal of Abnormal Psychology,121, 971-977, DOI: $10.1037 / \mathrm{a} 0028355$

Lahey, B. B., Zald, D. H., Hakes, J. K., et al. (2014). Patterns of heterotypic continuity associated with the cross-sectional correlational structure of prevalent mental disorders in adults. JAMA Psychiatry, 71, 989-996, DOI:10.1001/jamapsychiatry.2014.359

Lim, Y. J. (2014). Psychometric characteristics of the Korean mental health continuum-short form in an adolescent sample. Journal of Psychoeducational Assessment, 32(4), 356-64. DOI: $10.1177 / 0734282913511431$

Luyten, P., Van Houdenhove, B., Pae, C., Kempke, S., \& Van Wambeke, P. (2008), Treatment of chronic fatigue syndrome: Findings, principles and strategies. Psychiatry Investigation, 5(4) 209-212, DOI: 10.4306/pi.2008.5.4.209 
Lyubomirsky, S., \& Nolen-Hoeksema, S. (1995). Effects of self-focused rumination on negative thinking and interpersonal problem solving. Journal of Personality and Social Psychology, 69, 176-190, DOI: 10.1037/0022-3514.69.1.176

Mah, L., Szabuniewicz, C., Alexandra, A. F., \& Fiocco, AJ. (2016). Can anxiety damage the brain? Current Opinion in Psychiatry, 29(1), 56-63. DOI: 10.1097/YCO.0000000000000223

McLaughlin, K. A., Borkovec, T. D., \& Sibrava, N. J. (2007). The effects of worry and rumination on affect states and cognitive activity. Behavior Therapy, 38(1), 23-38, DOI: 10.1016/j. beth.2006.03.003

Merrick, M. T., Ford, D., Ports, K. A., \& Guinn, A. S. (2018). Prevalence of adverse experiences from the 2011-2014 Behavioral Risk Factor Surveillance System in 23 states prevalence of adverse childhood experiences from the 2011-2014. JAMA Pediatrics, 172(110), 10381044, DOI: 10.1001/jamapediatrics.2018.2537

Mustakova-Possardt, E. (2002). Three basic principles of psychological functioning: Exploring the possibilities of Mind, Consciousness and Thought ecology. Unpublished Monograph. (Available from elemam@west.edu).

Muktananda. S. (1992). Mystery of the mind. South Fallsburg, NY: SYDA Foundation.

Ottaviani, C., Thayer, J. F., Verkuil, B., Lonigro, A., Medea, B., Couyoumdjian, A., \& Brosschot, J. F. (2016). Physiological concomitants of perseverative cognition: A systematic and metaanalysis. Behavior Therapy, 38, 23-38, DOI: 10.1037/bul0000036

Papadopoulos, A. S., \& Cleare, A. J. (2012). Hypothalamic-pituitary-adrenal axis dysfunction in chronic fatigue syndrome. Nature Reviews Endocrinology, 8, 22-32, DOI: 10.1038/ nrendo.2011.153

Pransky, J., \& Kelley, T. M. (2017). How the formless comes into form: A process by which Universal Mind powers consciousness and thought to create people's psychological lives. Cogent Psychology, 4:1, DOI: 10.1080/23311908 .2017.1307633

Pransky,J., \& Kelley, T, M.(2014). Three principles for realizing mental health:Anew psycho-spiritual view. Journal of Creativity in Mental Health, 9, 53-68. DOI: 10.1080/15401383.2013.875864

Proctor, C. L., Tsukayama, E., Wood, A. M., Maltby, J., Eades, J. F., \& Linley, P. A. (2009). Strengths gym: The impact of character strength-based intervention on the life satisfaction and well-being of adolescents. Journal of Positive Psychology, 6, 377-388, DOI: 10.1080/17439760.2011.594079

Rank, O., Rictor, G. C., \& Lieberman, E. J. (2015). Psychology and the Soul. Journal of Religion and Health, 35(3), 193-201.

Reece-Evans, D., \& Pevalin, D. J. (2017). Using the principle-based model to improve well-being in school: A mixed-methods pilot study. 2017, Sage Open. DOI:10.1177/2159244017716217.

Ronald, A. (2019). Editorial: The psychopathology $p$ factor: will it revolutionize the science and practice of child and adolescent psychiatry? The Journal of Child Psychiatry and Psychology, 60(5), 497-499, DOI:10.1080/02796015.2008.12087908

Rusting, C. L., \& Nolen-Hoeksema, S. (1998). Regulating responses to anger: Effects of rumination and distraction on angry mood. Journal of Personality and Social Psychology, 790-803, DOI: 10.1037//0022-3514.74.3.790

Salama-Younes, M. (2012). Validation of the Mental Health Continuum Short Form and Subjective Vitality Scale with Egyptian adolescent athletes. In: Human pursuit of well-being: A cultural approach (p. 221-234). New York: Springer. 
Sedgeman, J. A. (1998). Reflections on the study of principles. Unpublished Manuscript. Morgantown, WV: West Virginia University School of Medicine.

Sedgeman, J. A., \& Sarwari, A. (2006). The effect of a health realization/innate health psychoeducation seminar on stress and anxiety in HIV-positive patients. Medical Science Monitor, 12(10), 397-399, PMID: 17006397.

Selzam, S., Coleman, J.R.I., Caspi, A. et al. (2018). A polygenic $p$ factor for major psychiatric disorders. Translational Psychiatry 8, 205, DOI: 10.1038/s41398-018-0217-4

Singh, K., Bassi, M., Junnarkar, M., \& Negri, L. (2015). Mental health and psychosocial functioning in adolescence: An investigation among Indian students from Delhi. Journal of Adolescence, 39, 59-69, DOI: 10.1016/j.adolescence.2014.12.008

Suldo, S. M., \& Shaffer, E. J. (2008). Looking beyond psychopathology: The duelfactor model of mental health in youth. School Psychology Review, 37, 52-68, DOI: 10.1080/02796015.2008.12087908

Tackett, J. L., Lilienfeld, S. O., Patrick, C. J, et al. (2017). It's time to broaden the replicability conversation: Thoughts for and from clinical psychological science. Perspective Psychological Science, 12, 742-756, DOI: 10.1177/1745691617690042

Teasdale. J. D., Scott, J., Moore, R. G., Hayhurst, H., Pope, M., \& Paykel, E. S. (2001). How does cognitive therapy prevent relapse in residual depression? Evidence from a controlled trial. Journal of Consulting and Clinical Psychology, 69(3), 347-357, DOI: 10.1037//0022006x.69.33347

Verkuil, B., Brosschot, J. F., Meerman, E. E., \& Thayer, J. F. (2012). Effects of momentary assessed stressful events and worry episodes on somatic health complaints. Psychological Health, 27, 141-158, DOI: 10.1080/08870441003653470

Watkins, E. R. (2008). Constructive and unconstructive repetitive thought. Psychological Bulletin, 134(2), 163-206, DOI: 10.1037/0033-2909.134.2.163

Zawadzki, M. J., Graham, J. E., \& Gerin, W. (2013). Rumination and anxiety mediate the effect of loneliness on depressed mood and sleep quality in college students. Health Psychology, 32(2), 212-222, DOI:10.1037/0033-2909.134.2.163 